\title{
Victory for female stem cells in battle of the sexes
}

Female muscle stem cells are better than those from males at regenerating lost muscle, according to research from the University of Pittsburgh Medical Center (PA, USA). So, although we may associate men with building more muscle than women, it would seem that women are more able to keep hold of what they have.

The team has been searching for a cure for Duchene muscular dystrophy, a genetic disease estimated to affect one in 3500 boys, in which patients lack dystrophin (a protein that gives muscle cells structure) and made their stem cell discovery as a result of this work. In this new study, female and male musclederived stem cells (MDSCs) were injected into dystrophic mice and the ability of the cells to regenerate dystrophin-expressing muscle fibers was then measured.

"Regardless of the sex of the host, the implantation of female stem cells led to significantly better skeletal muscle cell regeneration," said Johnny Huard, the study's senior author and director of the Stem Cell Research Center at Children's Hospital of Pittsburgh and Deputy Director of the McGowan Institute of Regenerative Medicine. "Based on these results, future studies investigating regenerative medicine should consider the sex of the stem cells to be an important factor. Furthermore, investigations such as ours could lead to a better understanding of sex-related differences in aging and disease and could explain, at least partially, the high variability and conflicting results reported in the literature on stem cell biology."

Although MDSCs regenerate skeletal muscle efficiently when transplanted into dystrophic mice, these cells exhibit heterogeneity in marker profiles and variability in regeneration abilities. The researchers show that cell sex is a variable with considerable influence over their regeneration ability because female MDSCs regenerated skeletal muscle much more efficiently than their male counterparts.

In calculating the regeneration index $(\mathrm{RI})$ that is, the ratio of dystrophin-positive fibers per 100,000 donor cells - the results show that only one of the ten male populations of implanted stem cells had a RI greater than 200 , whereas, by contrast, $40 \%$ of the female stem cell populations had a RI greater than

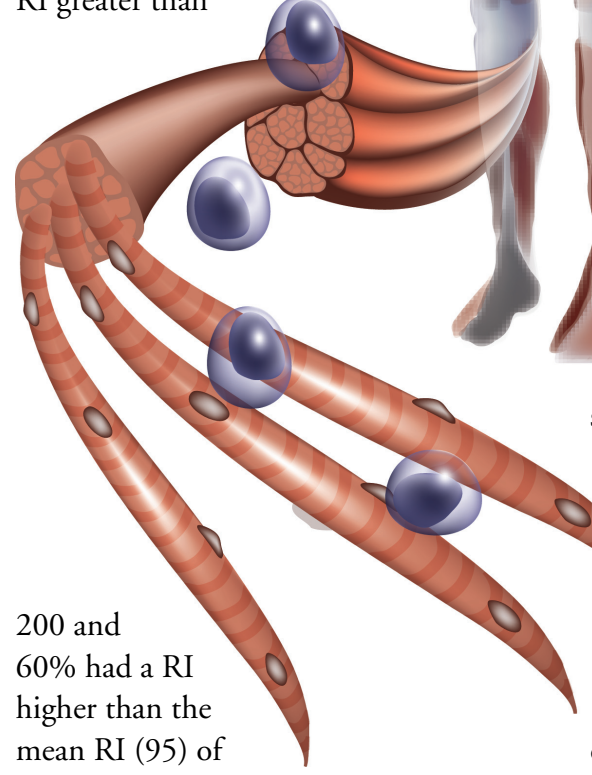
the male cells.

"The major difference was what we observed after exposing the cells to stress or after cell transplantation in the animals that have muscular dystrophy. Transplantation of female cells leads to a much more significant level of skeletal muscle regeneration," said Bridget Deasy, first author of the study. "The

male cells exhibited increased differentiation after exposure to oxidative stress, which may lead to cell depletion and a proliferative advantage for female cells after cell transplantation."

The difference between the cell sexes appears to be the result of innate sex-related differences in the stress response of the cells, rather than because of hormone levels or the host immune response. The female cells also appear to be better equipped to deal with the hypoxic conditions and reactive oxygen species, found in injured and diseased muscle, by upregulating more stress-related and antiapoptotic genes than the male cells.

This study is the first ever to report a difference in the regenerative capabilities of muscle stem cells based on sex, although the researchers are still to determine the ultimate cause of the

female cells' superior regenerating ability.

However, the results could have a major impact on the successful development of stem cells as viable therapies for various diseases and the designers of future stem cell studies should consider cell sex as a variable and consider the possible implications of relying on the cells of only one sex.

Source: Deasy BM, Lu A, Tebbets JC et al:: A role for cell sex in stem cell-mediated skeletal muscle regeneration: female cells have higher muscle regeneration efficiency. J. Cell Biol. 177, 73-86 (2007). 


\section{in brief}

Successful differentiation of mouse neural stem cells on layer-by-layer assembled single-walled carbon nanotube composite.

Jan E, Kotov NA: Nano Lett. [Epub ahead of print] (2007).

This study demonstrates that mouse embryonic neural stem cells from the cortex can be differentiated successfully to neurons, astrocytes and oligodendrocytes, with clear formation of neuritis on layer-by-layer assembled single-walled carbon nanotube (SWNT) polyelectrolyte multilayer thin films. Neural stem cells are very plastic neural precursors that can adapt to environmental conditions and can recreate signal transduction pathways. SWNTs are resistant to corrosion, strong and demonstrate electron conductivity, all properties that are essential for neuroprosthetic devices. These researchers have found that the biocompatibility, neurite outgrowth and neural marker expression of the neural stem cells on the SWNT films were similar to those differentiated on poly-L-orthinine, which is one of the most widely used growth substratums for neural stem cells.

Activation of endogenous neural stem cells in the adult human brain following subarachnoid hemorrhage.

Sgubin D, Aztiria E, Perin A, Longatti $P$, Leanza G: J. Neurosci. Res. [Epub ahead of print] (2007).

Little information is available regarding the occurrence of neurogenesis in the human brain under pathological conditions, such as stroke, traumatic injury, seizures and hemorrhage, although it is known that neural stem cells are present in the subgranular layer of the dentate gyrus of the hippocampus and in the subventricular zone of the lateral ventricles. This study reports on neural progenitor cell proliferation in the brain of those suffering from subarachnoid hemorrhage (SAH) following ruptured aneurysm. SAH patients express a variety of markers consistent with CNS progenitor cells, whereas no gene/protein expression profiles were detected in the control tissue samples. These results suggest that neural progenitor cell proliferation may be activated within the adult human brain following $\mathrm{SAH}$ and that this could contribute to the promotion of spontaneous recovery.

\section{Stem cells to decrease ischemic injury and restore brain function? What a stroke of luck}

A new study, published recently by Public Library of Science One, has found that stem cells can decrease ischemic injury and restore brain function in a murine model. These results raise hope for stroke sufferers because, despite recent advancements in the management of ischemic patients, stroke is still a major and unresolved medical issue.

"Stroke causes the death of many nervous cells that, in theory, could be substituted by stem cells. A few studies have shown that these cells can be effective, although various issues about their use and the mechanisms of their protective action remain unresolved," says Maria Grazia De Simoni. "Our research has underlined a possible mechanism of action."

Neurospheres are free-floating heterogeneous aggregates of various progenitors and differentiated cells, as well as a minority of neural stem cells. Under certain culture conditions, these cell clusters can produce neurons, astrocytes and oligodendrocytes. Neurosphere-derived cells (NCs) have been used previously in various experimental models of brain or spinal cord injury.

The researchers, from the Mario Negri Institute and the Instituto Neurologico Besta in Milan (Italy) and the University of Lausanne (Switzerland), therefore used a murine model of focal, transient ischemia to determine: whether infused NCs (obtained from newborn C57/BL6 mice) decrease and restore brain function; whether NCs induce environmental changes where they are infused; and whether changes in the brain environment following ischemia are relevant for $\mathrm{NC}$ action.

When administered $4 \mathrm{~h}$ after transient focal ischemia, NCs counteracted the ischemia/reperfusion injury effectively in the in vivo animal model, in part by significantly decreasing neuronal loss. The NCs also provided a protective effect against impairment in exploratory behavior and sensory-motor activity as early as 1 week following ischemia.

The authors believe that their study is the first to show functional recovery and reversal of neurodegeneration by NCs in ischemic injury. These infused cells included different stages of multipotent stem cells and, in this study, the majority of NCs maintained their undifferentiated features, thus indicating an abundance of immature neurons and astrocytes. The authors therefore hypothesized that the protective action of the NCs was a result of a bystander mechanism.

"Once introduced in the area of the brain hit by a stroke, stem cells induce the development of a protective effect in this same area," says De Simoni.

"Therefore, it is not necessary, as proposed in past studies, for stem cells to turn into neurons in order to protect the brain from ischemic injury and restore brain functions. Their presence in brain tissue is sufficient to induce a protective reaction."

Several cell types are involved in this reaction, including microglia. These cells have always been thought to have a toxic and inflammatory effect; however, it seems from this new research that the NC protective effect relates to microglia/macrophage activation. “...we suggest that the microglia also has a protective function," explains De Simoni. "Moreover our research shows that these cells survive in brain tissue only for a few days and then they are eliminated. This is very important given the possibility that stem cells may turn into cancer cells."

Source: Capone C, Frigerio S, Fumagalli S et al: : Neurosphere-derived cells exert a neuroprotective action by changing the ischemic microenvironment. PLoS ONE 2(4), e373 [Epub ahead of print] (2007). 


\section{Stem cell-derived heart valves could become clinically viable in $3-5$ years}

A multidisciplinary team of scientists led by Sir Magdi Yacoub, one of the world's leading heart surgeons and Professor of cardiac surgery at Imperial College London (UK), has successfully used adult stems cells to develop tissue that, in the laboratory, works in the same way as human heart valves.

'... owing to the high
prevelance of cardiovascular
disease, by $2010,600,000$
people around the world will
need replacement heart
valves.'

The WHO estimates that, owing to the high prevelance of cardiovascular disease, by 2010, 600,000 people around the world will need replacement heart valves. "You can see the common pathway of death and suffering is heart failure," said Yacoub. "Reversing heart failure could have a major impact."

There are several types of heart valve that regulate the flow of blood through the heart. Diseases, both inherited and acquired, can affect the valves in many different ways. They can become inflamed, prolapse, fail to open and shut correctly and can leak and narrow.

At present, one of the main hurdles to effective treatment is the lack of donor hearts that can be used for transplantation.

Yacoub's research group have been working on overcoming this hurdle over the last 10 years by characterizing how each part of the heart works and then utilizing stem cells to replicate those parts. Stem cell-derived heart tissue would overcome the aforementioned rejection issues. Eventually, the aim is to utilize the same techniques to grow a complete heart.
Yacoub said, "It is an ambitious project but not impossible. If you want me to guess I'd say 10 years, but experience has shown that the progress that is happening nowadays makes it possible to achieve milestones in a shorter time. I wouldn't be surprised if it was some day sooner than we think."

However, other scientists, while applauding the findings, have cautioned that it may be many years before the work that has been demonstrated in the laboratory can be replicated in living animals and, as such, the work is still in its infancy.

\section{'... it may be many years before the work that has been demonstrated in the laboratory \\ can be replicated in living animals...'}

The multidisciplinary team developed the heart valve cells by taking adult stem cells from bone marrow. They used collagen, a protein of great tensile strength, as a scaffold for tissue to grow upon.

'The multidisciplinary team developed the heart valve cells by taking adult stem cells from bone marrow.'

Artificial heart valves are available, however, they do present a number of problems for the patient, namely rejection issues as with donor valves, both which require the need for lifelong administration of immunosuppressants, rendering the patient more vulnerable to disease. In addition, artificial valves are unable to provide a number of the sophisticated functions of living tissue.
"The way a living valve functions, it anticipates hemodynamic events and responds and changes its shape and size. It's completely different from an artificial valve which will just open and shut. The heart muscle itself will appreciate something which will make it free to contract properly," said Yacoub.

'...because the patient's own stem cells are used it eliminates the problem with rejection that happens when a heart has been donated by another person.'

British Heart Foundation Professor John Martin said that the stem cell method has two advantages for patients: "Firstly, the tissue produced in the laboratory might be used instead of putting the patient through a heart transplant. Secondly, because the patient's own stem cells are used it eliminates the problem with rejection that happens when a heart has been donated by another person."

If animal trials, scheduled later this year, are successful, the result of this research could be stem cell-grown heart valves being used in transplant surgery within 3-5 years.

The progress of Yacoub's team and that of his colleagues around the world will be published in August in a special edition of the journal Philosophical Transactions of the Royal Society.

Sources: Imperial College London myocardial regeneration and valve tissue engineering website www.imperial.ac.uk/medicine/about/divisions/nhli/cardio/heart/regrep/myoreg/ Medical News Today website www.medicalnewstoday.com/healthnews.php? newsid $=67070$ 


\section{Stem cells offer hope for Type 1 diabetes sufferers}

A recent study, published in the April issue of the Journal of the American Medical Association, has shown promising results for the use of stem cells in the treatment of Type 1 diabetes.

Researchers from the USA and Brazil investigated the effects of stem cell transplantation in 15 newly diagnosed insulin-dependent diabetics aged 14-31 years. Firstly, the 15 patients received drugs to stimulate stem cell production. Bone marrow was then removed to harvest a supply of the patients' own blood stem cells. Richard Burt, of Northwestern University (IL, USA), and coauthor of the study explained, "These are not embryonic stem cells. These are your own circulating blood stem cells from the patient themselves." Following suppression of their immune system by chemotherapy, each patient received transfusions of their own stem cells.

\section{'The study...found impressive \\ results, with 14 out of the 15 patients experiencing a loss of insulin-dependence.'}

The study, which ran from November 2003 to July 2006, with further observation until February 2007, found impressive results, with 14 out of the 15 patients experiencing a loss of insulindependence. The treatment was shown to be safe in all participants.

One patient remained insulin injection-free almost 3 years after treatment; a further four did not require insulin injections for at least 21 months. The average length of time the patients remained insulin injection-free was approximately 19 months.

During treatment and follow-up, blood samples were taken from each patient and their levels of insulin and other markers were identified. The levels of C-peptide were found to be significantly higher 6 months following treatment than before the stem cell transplantation. This increased level did not change at both 12 and 24 months.

"This is the first time in the history of diabetes that all patients have gone an interval up to 3 years - and perhaps longer, only time will tell - requiring no treatment, no insulin, no immune suppression, no medication at all," Burt commented.

The authors are cautious, stressing that research is only in its early stages, but optimistic, hoping that this research will pave the way for further studies into possible novel treatments for diabetes.

Source: Voltarelli JC, Couri CE, Stracieri AB et al: Autologous nonmyeloablative hematopoietic stem cell transplantation in newly diagnosed Type 1 diabetes mellitus. JAMA 297(14), 1568-1576 (2007).

\section{Stem cell therapy shows promise for rescuing deteriorating vision}

A new study in rats has used neural progenitor cells, formative brain cells that arise in early development, derived from human fetal stem cells in an attempt to restore vision. The cells show some of the best rescue, functionally and anatomically, from degenerative eye disorders in animals whose eyesight was likely to be lost from degenerative disease.

David Gamm, the lead author of the study at the University of WisconsinMadison (WI, USA), explained that the animal models of disease showed close similarities to human eyes and the degenerative diseases that afflict humans.

Macular degeneration is the leading cause of registered blindness for people aged over 50 years in the western world and, currently, there are no effective methods for preserving eyesight in patients suffering from degenerative eye disease.

The stem cells were being examined for their ability to deliver a specific growth factor in models of Parkinson's disease and Lou Gehrig's disease, but it was uncovered that the cells alone actually appeared to show an ability to rescue vision.

The new findings appear in the journal Public Library of Science One and suggest that there may be novel ways to preserve vision. The results came as a surprise according to Raymond Lund, an author of the study and an eye disease expert at the University of Utah (UT, USA).

The cells were being used to move glial cell line-derived neurotrophic factor (GDNF) into the eyes as a continuous delivery system, in order to be able to avoid repeated injections to the eyes. Lund commented that, "The idea was to use the cells as a continuous delivery system, but we found they work quite well on their own."

Lund explained, "On their own, they were able to support retinal cells and keep them alive".
He continued "We didn't expect that at all. We've used a number of different cell types from different sources and these have given us the best results we've ever got."

David Gamm explained the novel use of progenitor cells, "This cell type isn't derived from the retina. It is derived from the brain," he added, "but we're not asking it to become a retina. They survive in the environment of the eye and don't disrupt the local architecture. They seem to live in a symbiotic relationship." He concluded, "It seems that the cells in and of themselves are quite neuroprotective. They don't become retinal cells. They maintain their own identity, but they migrate within the outer and inner retina."

The authors agree that further research is required to understand how the cells.

Source: Gamm DM, Wang S, Lu B et al: Protection of visual functions by human neural progenitors in a rat model of retinal disease. PLoS ONE 2(3), e338 (2007). 


\section{in brief...}

No evidence for vasculogenesis regulation by angiostatin during mouse embryonic stem cell differentiation.

Prandini MH, Desroches-Castan A, Feraud O, Vittet D: J. Cell. Physiol. [Epub ahead of print] (2007)

The authors analyzed the potential role of angiostatin, which is a proteolytic fragment of plasminogen and inhibitor of angiogenesis, during the early stages of embryonic stem cell endothelia in vitro differentiation (a model of vasculogenesis, which is involved in the formation of new blood vessels). Early expression of the known angiostatinbinding sites was detected during embryonic stem cell differentiation, although no significant effect of angiostatin on mesoderm induction or differentiation commitment into cells of the endothelial lineage was observed. The findings support a selective inhibitory effect on the sprouting angiogenesis response for angiostatin during embryonic vascular development.

\section{Surface patterning: tool to modulate stem cell} differentiation in an adipose system.

Chaubey A, Ross KJ, Leadbetter RM, Burg KJ:

J. Biomed. Mater. Res. B Appl. Biomater. [Epub ahead of print] (2007).

The efficacy of D1 cells, multipotent mouse bone marrow stromal precursors, in differentiating to fat and the characterization of their metabolic activity and lipid production when cultured on patterned poly-L-lactide films was evaluated. The appropriate stimulation caused D1 cells to display

morphological characteristics of adipocytes and to produce lipid, and the results show that patterned surfaces affected the rate of lipid production.

Further information regarding cell interactions with the microtopography of an implant surface could push breast tissue engineering towards clinical use.

Both $P d x-1$ and NeuroD1 genes are requisite for the maintenance of insulin gene expression in ES-derived differentiated cells. Saitoh K, Yamato E, Miyazaki S, Miyazaki Jl: Diabetes Res. Clin. Pract. [Epub ahead of print] (2007).

The authors established an embryonic stem cell line in which exogenous $P d x-1$ expression is regulated precisely by the Tet-off system integrated into the ROSA26 locus and have succeeded in producing insulin-producing cells. These $P d x$-1-expressing insulin-positive cells were maintained for over 2 months; however, repeated passages of cells lost their capacity to express insulin and the NeuroD1 gene. Forced NeuroD1 expression by adenoviral vector restored insulin expression in these cells. The results suggest that maintenance of the insulinproducing property of embryonic stem cells could be achieved by synergistic expression of $P d x-1$ and NeuroD1.

Fat removed during liposuction is being studied for molecular markers to find stem cells that can aid in regeneration.

\section{Liposuctioned fat as a novel source of stem cells}

Philippe Collas from the University of Oslo (Norway) has identified certain chemical markers that allow him to predict which, among the hundreds of millions of stem cells in fat, are best at regenerating tissue. Unwanted fat removed during liposuction is an "underappreciated source of stem cells," states Collas, which have the potential to heal injuries and repair defects in the body.

\section{'Unwanted fat removed during liposuction is an \\ "underappreciated source of stem cells"...}

Collas presented his findings at the EuroSTELLS Workshop Exploring Chromatin in Stem Cells held on January 22-24, in Montpellier, France. He said that "the discovery of these molecular tags could enable the taking of a patient's own fat cells to use for therapy".

EuroSTELLS is the European

Collaborative Research

(EUROCORES) programme on

Development of a Stem Cell Tool

Box, developed by the European Science Foundation.

'Despite the successes seen so

far, some believe that stem cells from fat only have limited potential as they believe that it is impossible to reprogramme adult stem cells to differentiate into cells of different tissues...'

Despite the successes seen so far, some believe that stem cells from fat only have limited potential as they believe that it is impossible to reprogramme adult stem cells to differentiate into cells of different tissues; this can only be achieved using embryotic stem cells. In response, Collas insists that this transformation is possible. He states that "the hurdle lies not with the genes but with a cell's epigenetic status, the subtle chemical modifications of DNA and its surrounding histone proteins". These epigenetic markers contribute to switching genes on and off, and stem cells rely on them heavily as they divide and mature. For example, Collas and his team found that low rates of DNA methylation boost the chances of a fat cell transforming into another cell type. Collas states that "if you look at a cells epigenetic profile you may be able to predict what a cell is likely to turn into".

Collas's findings were backed up by Ernest Arenas, a EuroSTELLS researcher at the Karolinska Institute in Stockholm, Sweden. "Scientists in the stem cell field are starting to realize that for cell manipulations to succeed they need to pay attention to their epigenetic marks. Cells can't be pushed along to become a different cell type unless they start out with the right set of [epigenetic] conditions".

"Cells can't be pushed along to become a different cell type unless they start out with the right set of (epigenetic) conditions"

The area of stem cells is undoubtedly complex, but these findings are loaded with promise. "Everyone is talking about epigenetics," says Collas. If these results can be substantiated then, in the future, people may well be visiting plastic surgeons for more than just cosmetic reasons.

Source: European Science Foundation EUROCORES programme www.esf.org/esf_pressarea_page.php?langua ge $=0$ \& section $=6 \&$ newsrelease $=165$ 


\section{Registry of embryonic stem cell lines agreed by European Commission}

Last month, the European Commission agreed to spend, over 3 years, approximately US $\$ 1.3$ million to create a registry of human embryonic stem cell (hESC) lines. A total of ten EU countries (Belgium, Czech Republic, Denmark, Finland, France, Germany, The Netherlands, Spain, Sweden and the UK), as well as Israel, Switzerland, Turkey and the USA, will be involved with the registry, which will be operated by the Center of Regenerative Medicine in Barcelona (Spain) and the Berlin-Brandenburg Center for Regenerative Therapies in Berlin (Germany).

In July 2006, ministers of the EU member states agreed to continue funding certain hESC research projects (but not activities that destroy embryos) until 2013. This agreement states that all projects must be approved by independent experts and will be subject to strict ethical reviews. According to the EU commissioner for science and research, Janez Potocnik, stem cell research will receive less than US\$38 million of the EU's US\$65 billion research budget for 2007-2013.

'...the registry will make the "most effective use of existing stem cell lines and avoid the unnecessary creation of new ones."'
Potocnik believes that the registry will make the "most effective use of existing stem cell lines and avoid the unnecessary creation of new ones". Currently, 81 ESC lines are being used in EU-funded research projects and the EU has a "strict and transparent environment" for the use of ESC in its research program, according to Potocnik.

Potocnik adds that the registry "will also be useful in the creation of common international standardization for the characterization of these stem cells, essential for progress toward new cures and therapies."

Source: Kaiser Daily Health Report www.kaisernetwork.org

\section{New Masters Degree in Stem Cell Technology}

In response to the urgent need to train new graduates in the emerging stem cell field, the University of Nottingham will run the first MSc in Stem Cell Technology from October 2007.

This one year, full-time course is an innovative project designed to introduce science, agriculture and medical graduates throughout the world to the cutting edge of stem cell research and wide-ranging applications. Taught in Nottingham's state of the art Wolfson Centre for Stem Cells, Tissue Engineering and Modelling (STEM) by world-class researchers, students will gain both theoretical and practical knowledge of stem cells and how they can be applied to biotechnology and human health. This course is intended to provide a strong foundation for those wishing to pursue further careers in stem cell scientific research, in legislative/managerial aspects of stem cell technologies, in clinical regenerative medicine and in stem cell commercialisation.

Further information can be found at http://www.nottingham.ac.uk/human-development/PGCOURSES/ or by e-mailing mscstem@nottingham.ac.uk
The University of Nottingham

\section{About the Bulletin Board}

The Bulletin Board highlights some of the most important events and launches in stem cell research and regenerative medicine. The editorial team welcomes suggestions for timely, relevant items. If you have newsworthy information, please contact:

Elisa Manzotti,

Editor, Regenerative Medicine,Future Medicine Ltd, Unitec House,

2 Albert Place, Finchley Central, London N3 1QB, UK

E-mail: e.manzotti@futuremedicine.com; Tel: +44 (0)20 8349 2033; Fax: +44 (0)20 83432313 